\title{
Patrones de movilidad en el Arcaico Tardío: II Región
}

Francisco MenA $^{1}$

\section{Introducción}

Numerosos estudios arqueológicos en el sector de vegas de Chiu Chiu, curso medio del río Loa, han permitido definir el complejo cultural fechado entre 3000 y 1500 AC (Gómez 1963; Orellana et al. 1973; Druss 1978) que por sus características se enmarca claramente en el contexto del Arcaico atacameño, aunque aún no se han evaluado en profundidad sus relaciones funcionales con otros sitios asignados a este período.

Existen diversas limitaciones para emprender esta labor, tales como la carencia de suficientes dataciones radiocarbónicas como para indagar en la naturaleza de estas relaciones sobre una base cronológica segura, pero la realidad arqueológica atacameña ofrece ciertas condiciones favorables para intentar un análisis inicial en este sentido.

En primer lugar, podemos suponer con bastante confianza que las condiciones medioambientales no han sufrido cambios radicales desde hace unos cinco mil años (Montecino 1980) y que, con pequeñas modificaciones, es posible interpretar el marco ecológico de los sitios arqueológicos en base al paisaje que observamos hoy.

Por otra parte, las condiciones de aridez y bajos índices de erosión facilitan la preservación y registro de evidencias prehistóricas, lo que es aún más fácil si consideramos que en esta región los lugares y vías favorables para la estadía de un grupo humano son escasos y bien localizados, coincidiendo en gran medida con las zonas que son más visitadas en la actualidad. Si bien es cierto que esta situación favorece la destrucción de las evidencias arqueológicas, permite suponer que un porcentaje importante de

1 Universidad de Chile, Santiago, CHILE. ellas han sido registradas en alguna forma, aunque estén en su mayor parte muy mal descritas.

En todo caso, los sitios utilizados con mayor frecuencia y duración por grupos relativamente numerosos ofrecen una mayor abundancia de materiales y son, por lo tanto, más "visibles" para fines de registro arqueológico. Son estos tipos de fenómenos los que mejor registra la metodología arqueológica, y aunque ello puede traducirse en un sacrificio de los detalles, variaciones y desviaciones de la norma, pone de relieve los mecanismos más frecuentes y regulares.

Es sobre este tipo de sistemas "normados" de movilidad que pretendemos arrojar alguna luz en este artículo, mediante el ejercicio de confrontar la data del Complejo Chiu Chiu con la de otros yacimientos de la II Región, de acuerdo a ciertos criterios que permitan identificar las relaciones de movilidad que articulan a este Complejo con su contexto regional durante el Arcaico Tardío.

Se escogió al Complejo Chiu Chiu como punto de referencia de las comparaciones, no solo por ser el evento que más conocemos $-\mathrm{y}$ uno de los mejor documentados de la región-, sino por su ubicación especialmente privilegiada, en la intersección de una serie de vías de tránsito hacia la región cordillerana, al altiplano, la cuenca del Salar de Atacama y la región costera (Figura 1).

\section{Patrones de movilidad}

Reconocemos que el problema considerado es demasiado amplio y complejo y que nuestro acercamiento no considera una recolección sistemática de información ni un análisis minucioso de la misma con miras a nuestros objetivos. La región de interés abarca varios $\mathrm{km}^{2}$ y los sitios registrados en ella superan un centenar, de los cuales sólo conocemos una decena en forma directa. Nuestra visión es demasiado general y distante para darnos el lujo de ser pretenciosos. 
Es por ello que renunciamos a "reconstruir" sistemas de movilidad particulares, considerando sus detalles y variaciones, y apuntamos nuestras observaciones hacia el reconocimiento de aquellos circuitos de movilidad más frecuentes, comunes y repetitivos.

Sin pretender desconocer la existencia de motivaciones socioculturales para los cambios en la localización de un grupo humano (p.e., resolución de conflictos, visitas sociales, festividades mágico religiosas, etc.), afirmamos que estos patrones de movilidad regulares y pautados tradicionalmente están determinados en primer lugar por la necesidad de mantener un equilibrio entre la demanda de una población y la provisión de recursos alimenticios disponibles desde un mismo lugar de asentamiento.

Pese a los hábitos y preferencias culturales del grupo humano, éstos nunca son tan caprichosos como para desestimar recursos alimenticios ricos y seguros, menos aún en ambientes pobres como el Desierto de Atacama. En consecuencia, podemos suponer que la movilidad de estas bandas dependía principalmente del comportamiento de los recursos alimenticios más seguros, y puesto que este estaba en relación al cambio de estaciones dentro del ciclo anual, creemos que éste es el marco temporal más adecuado para estudiar "patrones de movilidad". La necesidad de proveerse de bienes de prestigio $\mathrm{u}$ otros elementos (p.e., material lítico) que no presentan variaciones en su oferta a lo largo del año, así como la ocurrencia de fenómenos esporádicos (p.e., sequías prolongadas, erupciones, plagas) o dependientes de un ciclo irregular supraanual (p.e., avances de la Corriente del Niño, lluvias estivales fuertes) que afectan la masa de alimentos disponibles, repercutirían en variaciones oportunistas en la movilidad de grupos, pero no afectarían los "patrones de movilidad" normales y más frecuentes, que son los que nos interesa visualizar en una perspectiva arqueológica generalizadora.

Usamos el concepto de "patrones de movilidad" para referirnos a aquellos desplazamientos residenciales periódicos, frecuentes y pautados tradicionalmente, sin negar por ello que alrededor de estos "patrones de movilidad" debieron registrarse numerosas variaciones, dentro del sistema de decisiones flexibles y oportunistas característico de la estrategia económica de los pueblos cazadores recolectores.

\section{Criterios y argumentos para la identificación de relaciones entre sitios}

\section{1) Elementos-tipo compartidos}

La especialidad funcional de los diversos yacimientos que conforman un circuito de movilidad y la escasa información estilística diagnóstica que ofrecen los instrumentos simples de los pueblos precerámicos, dificultan la identificación de un mismo grupo humano en diferentes contextos medioambientales. La ausencia de rasgos compartidos no es prueba concluyente de que dos sitios representan campamentos de distintos grupos humanos, pues una misma banda pudo realizar actividades diferentes y utilizar, por lo tanto, un variado instrumental, en los distintos lugares visitados a lo largo del año. Sin embargo, la presencia de un mismo elemento en sitios distantes se considera por lo general un indicador más directo del funcionamiento de circuitos de movilidad o contactos entre grupos.

Para que este tipo de interpretación sea válida debe basarse en elementos complejos con significación estilística, y en descripciones minuciosas que permitan comparaciones precisas, las que, por lo general, no existen.

$\mathrm{Al}$ aplicar al arcaico atacameño este argumento de identificación de grupos (y relaciones), por elementos-tipo, utilizaremos en primer lugar las puntas de proyectil y microperforadores -instrumento abundante y característico en el Complejo Chiu Chiu (Figuras 2 y 3 ) - y como evidencia complementaria otros elementos del contexto instrumental (p.e., morteros, estructuras habitacionales semicirculares en depresiones, etc.).

\section{2) Contemporaneidad}

La ambigüedad de muchas descripciones de material y el problema de la connotación funcional de estos elementos, que restringe su uso a determinados medio ambientes, hace necesario la consideración de fechados radiocarbónicos absolutos que establezcan una base de contemperaneidad sobre la cual poder establecer comparaciones.

Aunque en los últimos años se ha incrementado nuestra información al respecto y se dispone de alrededor de 30 fechados radiocarbónicos para el Arcaico Tardío en el Norte Grande (Núñez 1978), ellos se refieren a unos pocos yacimientos bien estudiados, y numerosos sitios que aparentemente corresponderían al 


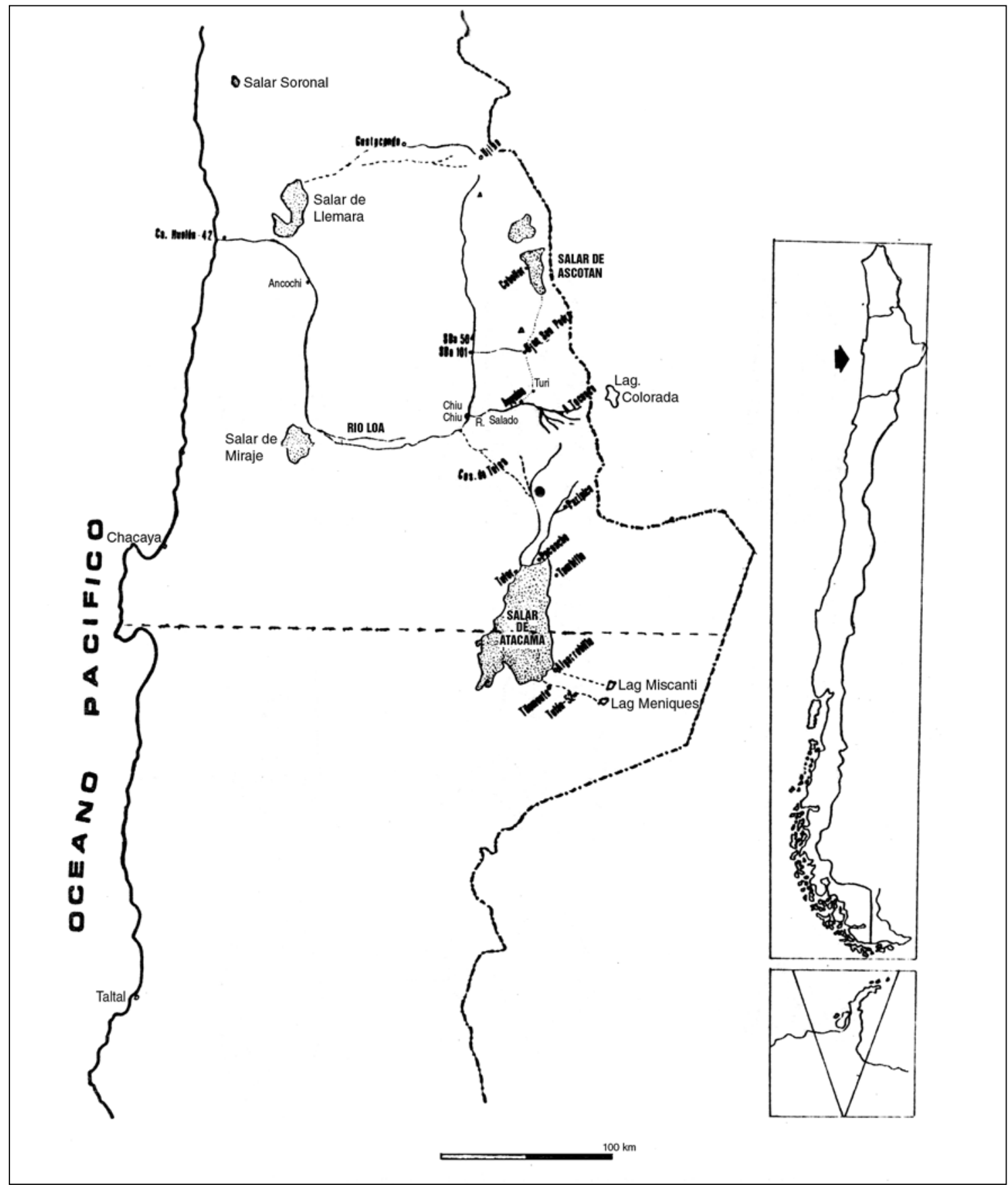

Figura. 1. Mapa de ubicación de sitios arqueológicos.

precerámico final y estarían relacionados con Chiu Chiu, carecen de una datación precisa.

\section{3) Complementariedad medioambiental}

En nuestro intento por identificar relaciones funcionales entre sitios, suponemos que si un grupo humano prehistórico desplaza eventualmente su residencia por motivos de insuficiencia de recursos, los diferentes sitios de campamento utilizados durante un ciclo de movilidad deben hallarse en medio ambientes que sustenten recursos variados y complementarios con períodos de abundancia discordantes.

Este criterio ha orientado implícitamente varias estrategias de prospección arqueológica en el Norte 


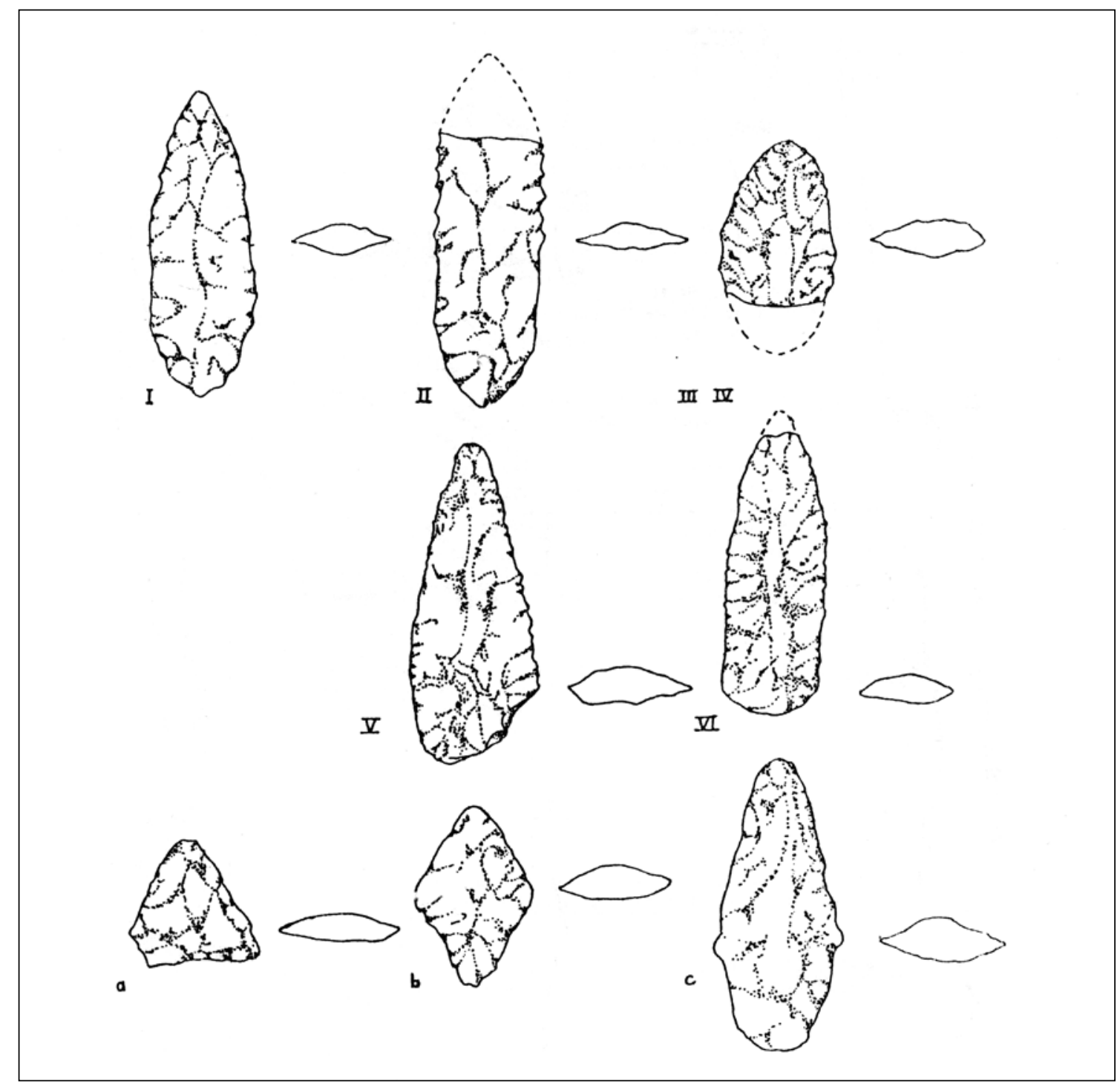

Figura 2. Tipos de puntas de proyectil Complejo Chiu Chiu. Tamaño natural.

Grande, complementando en ocasiones con el survey de cursos hídricos, que en estas regiones áridas son las principales rutas de tránsito (Núñez y Varela 1968; Núñez et al. 1975). Aunque la aplicación de este argumento nos enfrenta a ciertos problemas de reconstrucción paleoecológica, sabemos que el medio ambiente regional no presentaba, en el período en estudio, radicales diferencias con el actual, y los principales pisos altitudinales, complementados con observaciones fisiográficas locales, permiten reconocer con bastante seguridad sitios que cumplan con este requisito de complementariedad medioambiental.

\section{4) Estacionalidad alternada}

Una vez determinada la contemporaneidad de dos sitios que presentan varios elementos en común y se hallan ubicados en microambientes complementarios y mutuamente accesibles, podemos considerar que las hipotéticas relaciones entre ellos tienen un alto grado de validez, pero para determinar con mayor precisión la naturaleza de estas relaciones es preciso disponer de evidencias empíricas respecto al momento en que cada uno de estos sitios habría sido ocupado dentro del ciclo anual, o dentro de otro marco temporal cualquiera en que haya funcionado el sistema de movilidad residencial. 


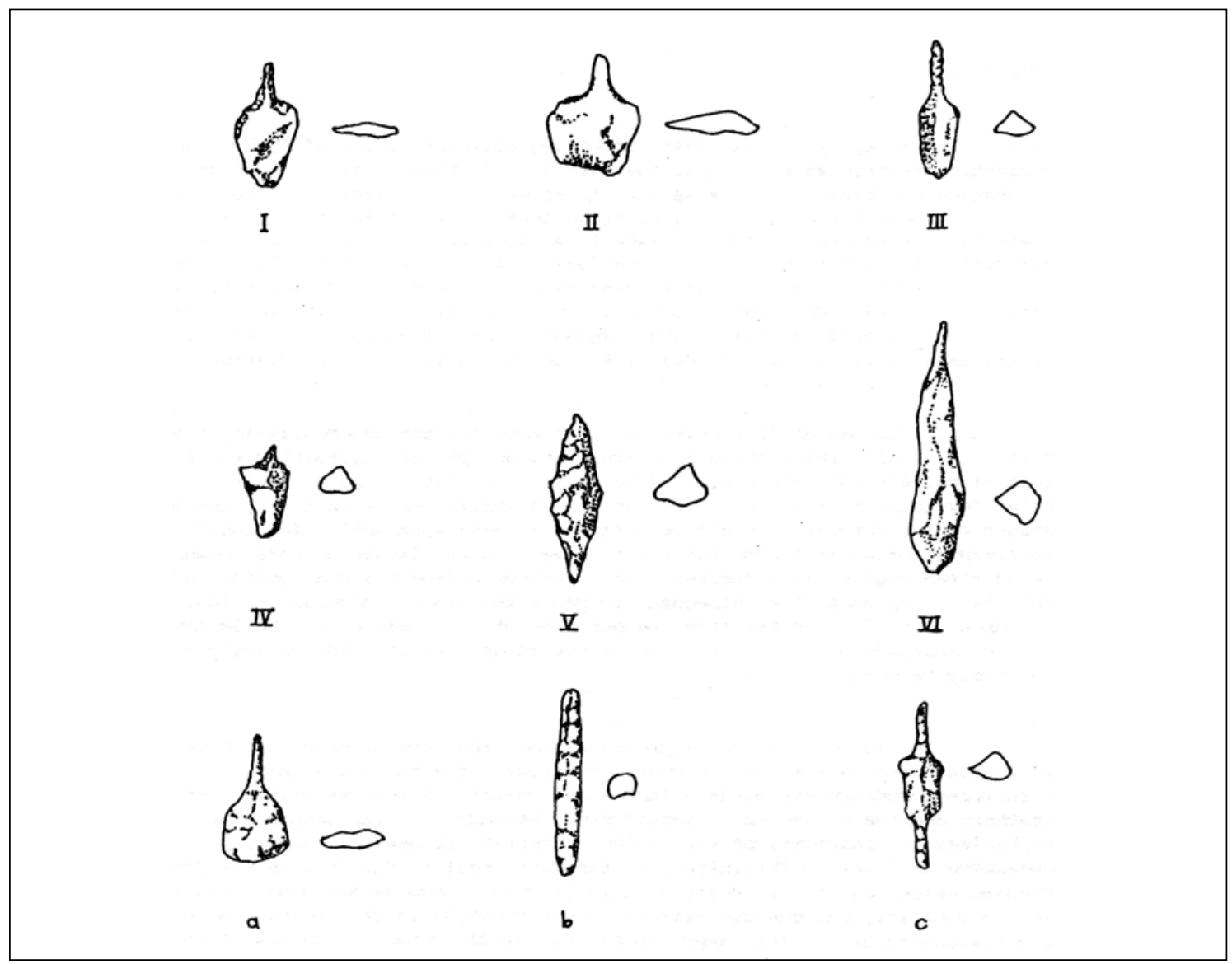

Figura 3. Tipos de perforadores Complejo Chiu Chiu. Tamaño natural.

El indicador más claro de estacionalidad lo constituyen ciertos rasgos de la evidencia faunística o vegetal asociada a las ocupaciones humanas, aunque no siempre resulta fácil detectar claramente esta asociación, ni inferir la estación que estas evidencias reflejan. Ejemplo de ello es el hallazgo de frutos de chañar o vainas de algarrobo, que aunque maduran y se recolectan a fines del verano, pudieron conservarse secos durante el otoño e invierno. La determinación precisa de edad de los auquénidos cazados, a través del análisis de las evidencias óseas halladas en los yacimientos, permitiría reconocer teóricamente la estación de ocupación de los sitios, pero los indicadores de edad que se conocen actualmente para estas especies son muy vagos, y los restos óseos se encuentran por lo general fragmentados y en mal estado de conservación como para someterse a este tipo de análisis.

Otros elementos que podrían servir, a falta de evidencias directas, para inferir la clase de actividades realizadas en un sitio y por consecuencia el momento del año en que fue ocupado, son los instrumentos. Este tipo de razonamiento supone, en primer lugar, un preciso conocimiento de la función de los instrumentos, la cual sería específica y relacionada exclusivamente con un uso y recurso determinado, lo que en ningún modo es exacto. Otro problema relacionado con la identificación de recursos usados a partir del análisis de los instrumentos, se refiere a que estos no siempre se encuentran asociados a ocupaciones dentro del medio ambiente y estación a que estaban destinados.

Durante el curso de sus desplazamientos, un grupo puede trasladar instrumentos de un lugar a otro, intercambiarlos con otros grupos o incluso aprovechar su paso por ciertas localidades con materias primas adecuadas para confeccionar algunas herramientas fáciles de transportar, destinadas a usarse en lugares lejanos. 


\section{Relaciones entre sitios: Evaluación crítica}

\section{1) Cuenca del Loa precordillerano}

Las condiciones de accesibilidad directa debieron facilitar especialmente el contacto entre las vegas de Chiu Chiu y otros puntos de la cuenca del río Loa, y se conocen varios sitios que al parecer evidencian esta relación emplazados a lo largo de dos vías principales: el río Loa mismo en su tramo superior y el río Salado y sus afluentes, convergiendo ambas en la vega inferior de Chiu Chiu.

Remontando el curso del río Loa, hallamos contextos arqueológicos similares a los del Loa Medio en sitios como SBa-101, en la confluencia con el río San Pedro, y SBa-50, situado unos 19 km más al norte. Ambos sitios se caracterizan por estructuras semicirculares, morteros de base redonda y cavidad cónica y material lítico muy semejante al de los sitios del Loa Medio, incluyendo perforadores típicos del Complejo Chiu Chiu (ver Figura 3), lo cual -unido a condiciones de accesibilidad y complementariedad altitudinal-apunta claramente al funcionamiento de algún sistema de movilidad a lo largo del río Loa por grupos arcaico tardíos. Aún no se practican estudios sistemáticos ni fechaciones en estos yacimientos (Berenguer et al. 1975).

Entre los sitios señalados, a unos $10 \mathrm{~km}$ aguas arriba desde la confluencia del San Pedro en el Loa, se encuentra la Cueva de la Damiana, sitio que presenta evidencias líticas y cerámicas de diversas clases y períodos en asociaciones confusas, seriamente disturbadas por acciones recientes. Esta situación impide evaluar con claridad sus posibles relaciones con otros campamentos del Arcaico Tardío en el valle, pero la revisión de los trabajos de Le Paige (1964-1970) y de colecciones provenientes del lugar nos ha permitido identificar algunas puntas de proyectil análogas a los tipos I y VI de Chiu Chiu (ver Figura 2), aunque hay ausencia de microperforadores.

En el curso alto del río Loa se desconocen contextos que puedan integrarse a este esquema hipotético de movilidad, aunque ello se debe en gran medida al desconocimiento arqueológico del sector. No hay razón para pensar que no hubiera sido visitado por los grupos a que hacemos referencia, menos aún si consideramos que el alto Loa es paso hacia el altiplano y los valles que descienden a Pampa del Tamarugal, utilizado hasta épocas históricas. Podría ser que algunos sitios del sector Lequena -que incluyen puntas tipo I, II y III- hayan desempeñado un papel en este problema, y tal vez haya evidencias de este tipo en las mismas fuentes del río Loa (p.e., Ujina-Rocas).

El argumento de complementariedad medioambiental permite suponer que los principales afluentes del Loa (que conectan el altiplano y las cuencas precordilleranas en distancias reducidas) debieron ser vías de desplazamiento frecuente. Es así como subiendo por el río San Pedro $36 \mathrm{~km}$ desde el punto de su confluencia con el Loa (donde se desplaza a modo de eje SBa-101) se accede al sector de vegas y vertientes de Ojos de San Pedro, a una altitud de 3960 m, donde Le Paige (1964) y Druss (1978) han identificado varios sitios con estructuras semicirculares, "microlitos" y puntas lanceoladas y triangulares que, aunque no han sido descritos adecuadamente, sugieren a este último investigador una relación funcional directa con Chiu Chiu. Desde este punto se tiene fácil acceso al sector de salares y el altiplano meridional, o bien al río Salado Superior.

Es curiosa la escasez de claras evidencias tipo Chiu Chiu a lo largo de esta vía fluvial, pudiendo por el momento referirnos al hallazgo de microperforadores aislados asociados a cerámica inicial en Ayquina (Los Morros II y III) y el estrato IV del Alero de Toconce, en donde se registran también asociados a cerámica del Período Medio (estrato III) (Orellana et al. 1969; Orellana 1970). Serracino (1975) menciona contextos en el curso superior del río Salado (Linzor, Mesada, Tatio 1 y 2) que adquieren especial interés en la perspectiva de probables desplazamientos hacia el altiplano (p.e., Laguna Colorada) y la cuenca del Salar de Atacama, pero no se dispone de descripciones precisas.

Tampoco conocemos suficientemente los yacimientos superficiales del sector de salares altiplánicos (p. e., Ascotán, Cebollar, San Martín, Ollagüe), fácilmente accesibles desde el Loa, los que se caracterizan por pequeñas puntas triangulares y acorazonadas y puntas lanceoladas pequeñas, cuyas diferencias con las del Loa Medio podrían explicarse por especialización funcional o uso de materias primas locales y no necesariamente por divergencias de "estilo" o identidad cultural.

\section{2) Cuenca del Salar de Atacama}

Al sur de la hoya del Loa precordillerano se extiende la gran cuenca cerrada del Salar de Atacama, 
conectada a través de los afluentes superiores del Salado o de las quebradas de Tuina, que convergen en el Loa al sur de Chiu Chiu y conforman en las serranías pasos hacia la cuenca del Salar, usados desde tiempos tempranos y en los que Druss (1978) identificó sitios que asigna al sistema Chiu Chiu.

En este ámbito, se conocen numerosos sitios precerámicos, con semejanzas de diverso grado con el Complejo Chiu Chiu. Esta relación se encuentra bien documentada en Puripica 1, campamento nucleado con estructuras circulares, puntas lanceoladas, microperforadores, raederas, raspadores y lascas de filo cortante, con fechas de $2865 \pm 70$ y 2100ะ95 AC (Núñez 1980). La escasez de morteros y obsidiana en el Loa Medio, que contrasta con su abundancia en este yacimiento, puede explicarse por diferencias de actividad que reflejan una situación de complementariedad medioambiental. En las fases tardías de Puripica se registra una relación aún más estrecha con los eventos Chiu Chiu, evidenciada en la coincidencia de rasgos específicos (estructuras circulares nucleadas, perforadores tipo " $b$ " y en el registro de conchas del Pacífico, que sólo pudieron llegar a través del Loa Medio. La estrecha semejanza entre los contextos artefactuales de ambos sectores, lo expedito de su mutuo acceso y su situación de contemporaneidad y complementariedad, ha permitido reconocer con bastante certeza su calidad de campamentos integrantes de un mismo sistema de movilidad-asentamiento (Bittmann et al. 1978).

Basta considerar el factor distancia para suponer que las relaciones entre los asentamientos del Loa Medio y los de la quebrada Tulan, al sureste del Salar de Atacama, fueron menos directas y frecuentes, pero las evidencias recuperadas en la "aldea" Tulan 52 y el taller aledaño Tulan 51A revelan ciertas relaciones con Puripica y -tal vez por su intermedio- con los sitios de Chiu Chiu (Núñez 1980). Los sitios se hallan emplazados en la sección inferior de la estrecha quebrada, $8 \mathrm{~km}$ al este de su desembocadura en vegas de Tilomonte y a una altitud de $3500 \mathrm{~m}$ y han sido fechados entre $3040 \pm 110$ y $2390 \pm 95$ AC (Núñez 1980). El contexto artefactual recuperado en estos yacimientos -contemporáneos en parte al desarrollo de Puripica 1 y el Complejo Chiu Chiu-comparte con este último puntas lanceoladas de varios tamaños, cuchillos en semiluna, raspadores de uña y microperforadores de sección triangular. Aunque en sus rasgos principiales el patrón constructivo presenta semejanzas con el de algunos sitios del Loa Medio, incluye elementos complejos característicos (depósitos en el piso, muros de lajas verticales) similares a los de algunos sitios de la costa del Pacífico (p.e., Caleta Huelén 42). La variedad de puntas de proyectil conocidas en Tulan reflejan el desarrollo de una tecnología cazadora altamente especializada, favorecida por condiciones locales de agua y forraje y por la cercanía a otros microambientes donde cazaban recursos variados con instrumentos que pudieron hacerse en talleres cercanos a las canteras, en las inmediaciones de Tulan 52 (Núñez 1980). El Loa Medio, en cambio, fue durante largos períodos un hábitat marginal, donde las condiciones de aridez sólo sustentaban ocasionalmente rebaños de camélidos que descendían de la alta Puna en inviernos particularmente húmedos (Druss 1978: 244), lo que probablemente da cuenta, en gran medida, de la homogeneidad morfológica de las puntas Chiu Chiu.

En las mismas orillas del Salar de Atacama se conocen varios yacimientos que debieron ser campamentos usados por estas bandas arcaicas, pero el hecho de que estos pisos han sido utilizados hasta hoy como asentamiento, dificulta la interpretación precisa de contextos.

Es en este microambiente rico en recursos, $27 \mathrm{~km}$ al sur de San Pedro de Atacama, donde se emplaza el sitio de Tambillo, pequeña loma extendida de poca altura en donde las evidencias cerámicas son escasísimas. Originalmente el sitio fue tipificado por la punta lanceolada y asociado a un Ayampitinense (Le Paige 1959), pero la revisión de colecciones de superficie hecha por Kaltwasser (1963) le llevó a concluir que los materiales más característicos del sitio son la punta tetragonal, en base a lo cual se relacionaría con yacimientos como Pelun, Calarcoco, Tumbre y otros ubicados en las quebradas intermedias entre el salar y la alta Puna (Serracino 1976, 1977) y, probablemente, los salares septentrionales (Barfield 1961).

Sin embargo, las excavaciones practicadas en el sitio (L. Núñez com. pers.) han entregado una alta frecuencia de puntas-cuchillos triangulares y otros elementos que hacen de Tambillo un componente bastante peculiar en el arcaico atacameño. Aunque no se dispone de fechados absolutos para este desarrollo, sus características generales sugieren que se enmarca dentro de esta fase, constituyendo probablemente un contexto tardío altamente especializado en la explotación de recursos lacustres y ribereños. Las puntas triangulares de base cóncava y perforadores 
de cuerpo ancho y delgado, típicamente Tambillo, aparecen en fases tardías del Complejo Chiu Chiu y coexisten con alfarería tosca en los sitios del Complejo Vega Alta (Pollard 1971).

Otros sitios de borde del Salar que -pese a su mezcla con materiales tardíos- deberían incluir componentes relacionados en algún modo con el Arcaico Tardío del Loa Medio, son Solor 6 y 7, Coyo y tal vez algunos yacimientos agroalfarero tempranos, como Tulor 1.

La evidencia de que disponemos actualmente permite vislumbrar con bastante claridad el funcionamiento, a partir de $3000 \mathrm{AC}$, de una serie de circuitos verticales paralelos que utilizaban las quebradas intermedias como vía de tránsito entre el borde del Salar y los pisos puneños, controlando así una serie de microambientes dentro de un espacio reducido y alcanzando a fines del arcaico un alto grado de estabilidad residencial, ubicándose en sectores ricos en recursos seguros y preferentemente equidistantes de los pisos de explotación alternativa, a los que accedían en determinados momentos del año, ya sea en grupos familiares o en forma de parcialidades masculinas especializadas. Dentro de este modelo, los yacimientos precerámicos en el borde de la puna -con su gran variedad estilística- podrían comprenderse como campamentos estivales de distintas bandas, en donde probablemente se establecieron contactos con portadores de tradiciones de la vertiente oriental de los Andes, en un momento en que las conchas del Pacífico ya llegaban a sitios como Huachichocana CH III (1450 AC), Inca Cueva 7 (2130 AC) y Atuel (1880 AC) y las influencias agroalfareras tempranas comenzaban a infiltrar el área atacameña.

\section{3) El litoral y la depresión intermedia}

Los contactos entre las cuencas precordilleranas y la costa también se hacen sentir en el registro arqueológico de sitios del litoral. Uno de los casos mejor conocidos es el del núcleo aldeano de Caleta Huelén 42 (Núñez et al. 1974) que presenta plumas de perico cordillerano, obsidiana altoandina y un patrón constructivo se ha reconocido muy semejante al de los sitios arcaicos de interior, con los cuales presenta además una situación de contemporaneidad ( $2830 \pm 100$ AC). Otros sitios de similares características, tales como Caleta Huelén 48 y algunos yacimientos de Cobija, parecen ser también reflejo de un momento en que el litoral (aparte de ser explotado regularmente por grupos especializados en la explotación marítima) recibía eventualmente a grupos del interior que establecían ejes terminales en un circuito trashumántico, dedicándose tanto a la caza de auquénidos y mamíferos marinos como a la explotación de recursos típicamente marítimos.

El desarrollo de circuitos de movilidad tan amplios a través de un paisaje extremadamente árido como lo es el Desierto de Atacama presenta una serie de problemas que están muy lejos de ser resueltos. Desde un punto de vista arqueológico, una de las mayores deficiencias de la hipótesis propuesta es la escasez de yacimientos asignables a estas poblaciones en la depresión intermedia, lo que podría explicarse por error de survey, considerando que los campamentos en este medio debieron ser sumamente transitorios. Probablemente algunos de los yacimientos superficiales en Ancachi y Quillagua tengan relación con estos eventos, y Druss (1978: 147) menciona la existencia de un sitio con materiales similares a los de Chiu Chiu cerca del salar de Miraje, que aunque se describe con vaguedad adquiere especial interés al tomar en consideración los recientes hallazgos en Cobija y el hecho de que esta ruta acorta el camino a la costa, permite evitar las aguas altamente salinas del bajo Loa y dispone de algunas aguadas que hacían de ella una ruta bastante transitada hasta principios de siglo.

Mejores condiciones para la estadía de grupos humanos ofrecen las quebradas meridionales de la Pampa del Tamarugal, y aunque aún faltan evidencias para identificar la presencia de grupos relacionados con el Arcaico atacameño en este ámbito, pensamos que no debe descartarse la posibilidad de que hayan sido usadas para descender a Soronal desde las cabeceras del Loa y acceder a la costa sur de Iquique, aunque se tratara de contactos débiles y esporádicos.

\section{Resumen y conclusiones}

La revisión de las evidencias asignables al Arcaico Tardío en la II Región desde el punto de vista de los cuatro argumentos presentados nos revela que los mecanismos de movilidad residencial cumplieron un rol de fundamental importancia en el desarrollo de un modo de vida arcaico de notable homogeneidad tecnológica y organizativa en la precordillera atacameña, así como en el surgimiento de la vida sedentaria y pastoril. 
Aunque es probable que a fines del Altitermal la abundancia y seguridad de recursos haya posibilitado el funcionamiento de circuitos de movilidad bastante estables, esta situación comenzó a cambiar hacia $3000 \mathrm{AC}$, cuando comienza a registrarse una tendencia a la desertificación y -lo que es quizás más importante- a la inestabilidad climática, con variaciones impredecibles de un año a otro. Los patrones de movilidad relativamente rígidos revelaron ser inadecuados frente a esta compleja dinámica medioambiental. Podemos comprender el Arcaico Tardío como un esfuerzo constante de adaptación a la situación Meditermal, en que se buscan respuestas flexibles dentro de una amplia gama de alternativas, con tendencia a alcanzar un sistema de subsistencia seguro y una cierta estabilidad residencial. Como había sido habitual, los patrones de movilidad se articulan verticalmente, utilizando de preferencia ciertas quebradas y ríos determinados; pero utilizando también una variedad de rutas alternativas, por lo que suponemos que las zonas territoriales eran extensas y la masa demográfica baja.

Esto resulta particularmente cierto con respecto a la cuenca del Loa precordillerano, donde las rutas eficientes en términos de recursos son pocas, y la capacidad de sustentación regional es más baja que la del Salar de Atacama, donde hay varias quebradas paralelas con agua y otros recursos que facilitan la transitabilidad y permiten acceder a microambientes complementarios en tramos relativamente cortos. Mientras que el río Loa es la única ruta viable de contacto entre pisos ubicados -por lo demás- a varios días de distancia, las quebradas orientales de la cuenca del Salar de Atacama habrían permitido el flujo simultáneo e independiente de varios grupos paralelos, lo que al parecer da cuenta del desarrollo de diferencias locales, que tal vez se reflejen en la existencia de varias formas de puntas, tales como la tetragonal de Tambillo, la pentagonal de Algarrobilla o las lanceoladas finas de Tilomonte, todas en microambientes análogos. Esta situación contrasta claramente con la homogeneidad estilística de los materiales de la cuenca del Loa, lo que parece revelar la existencia de una mayor relación entre los grupos de esta región, aunque carecemos de estudios minuciosos y es probable que los fechados radiocarbónicos destaquen como variaciones contemporáneas algunos contextos cuyas diferencias se han explicado por diacronía.

En el actual estado de nuestros conocimientos, podemos señalar que la región del Loa fue ocupada más intensamente durante los primeros momentos del Meditermal, siendo paulatinamente deshabitada a medida que el medio ambiente se hacía más inhóspito, para convertirse finalmente en territorio anual de unos pocos y pequeños grupos solamente, mientras que las poblaciones establecidas en la cuenca del Salar de Atacama accedían ocasionalmente a ella, ya sea por causa de una baja crítica en la provisión alimenticia de sus territorios habituales, para explotar los recursos líticos existentes en el Loa Medio o para descender a la costa e intercambiar con los grupos del sector de Chiu Chiu elementos provenientes de la franja litoral. No debe entenderse este proceso de desertificación como algo constante y absoluto, sino más bien como una tendencia general en el marco de amplias fluctuaciones, que permitieron incluso momentos de alza en las precipitaciones (p.e., Fase 9, 2000 AC), en que el sector Chiu Chiu concentró poblaciones con un cierto nivel de estabilidad (Druss 1978). Sin embargo, no hay dudas de que el sector fue más rico en los momentos iniciales del Complejo Chiu Chiu y es en estas fases donde se registra según Druss (1978) el mayor número de sitios (6.9\%), más de la mitad de los cuales reflejan ocupaciones relativamente prolongadas en condiciones ambientales húmedas. En esta época habitaron la región grupos con patrones de movilidad relativamente estables a lo largo del Loa, estableciendo ejes en tierras altas y accediendo ya con cierta regularidad al sector de desembocadura.

A fines del tercer milenio, la cuenca del Loa pasó a ser una zona marginal explotada por algunos grupos con sistemas de movilidad altamente flexibles, mientras que en las quebradas orientales del Salar de Atacama se fue desarrollando gradualmente una mayor estabilidad residencial posibilitada por el fácil y rápido acceso a distintos pisos altitudinales, lo que explicaría la localización en la sección media de las quebradas de algunos asentamientos nucleados como Tulan 52 y Puripica $1 .^{2}$

Este "reordenamiento" de los sistemas de subsistencia después del desafío impuesto por el Meditermal, se tradujo en una mayor preocupación por el tráfico de bienes de prestigio, como se observa en el registro de abundantes cuentas de collar y conchas del Pacífico, cuya obtención implica necesariamente para los

\footnotetext{
Ver estudios de Núñez sobre tempranos patrones de movilidad y tráfico concernientes a esta región (Núñez 1978, 1981, 1983a, 1983b, 1984).
} 
grupos de la cuenca meridional una reactivación de los contactos con el Loa Medio, como se observa de hecho por la presencia de muchos elementos comunes en los sitios de Chiu Chiu y Puripica, a partir de $1500 \mathrm{AC}$. Es muy probable que estas poblaciones de las quebradas septentrionales de la cuenca del Salar, relacionadas más directamente con el Loa Medio, hayan jugado un importante rol en el intercambio de conchas y chert con los grupos meridionales. Este flujo de bienes de prestigio desempeñó también un papel importante en la llegada de elementos propios de los desarrollos agroalfareros incipientes en el altiplano.

Por esta época, algunos grupos de las quebradas intermedias del Salar estaban controlando inicialmente rebaños en una relación de semidomesticación y es probable que, como postulan Bittmann y colaboradores (1978), las vegas de Chiu Chiu hayan sido utilizadas ocasionalmente por estas poblaciones como pisos forrajeros en inviernos particularmente rigurosos. Estos campamentos estacionales sirvieron ocasionalmente de base para ocupaciones bastante estables y prolongadas, con un énfasis importante en la recolección de semillas y otros alimentos vegetales, lo cual configura una situación especialmente favorable para la adopción de las innovaciones agroalfareras que comienzan a manifestarse en la región a fines de este período. Difundidas desde el Altiplano Meridional a través de las mismas rutas y circuitos de movilidad que funcionaban anteriormente nos encontramos con las primeras evidencias alfareras en contextos típicamente arcaicos tales como Coyo y Solor 7 (Serracino 1974: 108), Los Morros III (Orellana et al. 1969: 127), Poconche y Tulor 1. En un principio este elemento debió considerarse casi exclusivamente como bien de prestigio, sin alterar el modo de subsistencia, aunque estos contactos con grupos alfareros iniciales se tradujeron en el desarrollo gradual de prácticas agrícolas que sumándose a las labores pastoriles y semisedentarismo aldeano preexistentes definieron un rápido desarrollo de un modo de vida netamente agroalfarero (p.e., Tulan 54, Chiu Chiu 200, Guatacondo, Tulor 1). El estudio de este proceso está en gran parte por hacerse y pese a que el problema ha sido abordado con cierta frecuencia en las investigaciones del Loa Medio, aún falta conocer lo que ocurrió entre la última fecha asignada a evidencias precerámicas (1975 AC) y la más antigua del Complejo Vega Alta (100 AC). Estudios en esta dirección han sido iniciados por Barón en la cuenca del Salar pero aún hace falta un estudio completo y sistemático del Agroalfarero Inicial en el altiplano boliviano, sin el cual será imposible integrar estos descubrimientos atacameños en un marco significativo.

Aunque aún hay muchos vacíos de información, y el presente ensayo tiene carácter de estudio tentativo preñado de hipótesis, esperamos que ayude a resaltar la importancia de los mecanismos de movilidad residencial en el desarrollo cultural de la II Región, considerándose como un factor esencial para comprender el pasado del hombre andino.

\section{REFERENCIAS CITADAS}

BARFIELD, L., 1961. Recent discoveries in the Atacama Desert and the Bolivian Altiplano. American Antiquity 27 (1): 93.

BERENGUER, J. et al., 1975. Reconocimiento arqueológico del río Loa Superior, sector Santa Bárbara. Boletín de Prehistoria de Chile 1.

BITTMANN, B., L. NUÑEZ y G. LE PAIGE, 1978. Cultura atacameña. Depto. Extensión Cultural del Ministerio de Educación, Santiago.

DRUSS, M., 1978. Environment, subsistence economy and settlement patterns of the Chiu Chiu Complex (ca. 2700 to 1600 BC) of the Atacama Desert, Northern Chile. Ph. D. Thesis. Columbia University Microfilms International, Ann Arbor.

GOMEZ, I., 1963. Taller lítico de Chiu Chiu, Provincia de Antofagasta. Tesis de Grado. Facultad de Filosofía y Educación, Universidad de Chile, Santiago.
JOCHIM, M., 1976. Hunter-gatherer subsistence and settlement: A predictive model. Academic Press, Nueva York.

KALTWASSER, J., 1963. Artefactos líticos de Tambillo. Antropología 1.

LE PAIGE, G., 1959. Antiguas culturas atacameñas en la cordillera chilena. Epoca Paleolítica. Revista Universitaria de la Universidad Católica 22.

— 1964. El Precerámico en la cordillera atacameña y los cementerios del Período Agroalfarero de San Pedro de Atacama. Anales de la Universidad del Norte 3, Antofagasta.

_ 1970. Industrias líticas de San Pedro de Atacama. Universidad del Norte, Editorial Orbe, Santiago.

LEE, R. e I. DEVORE (Eds.), 1977. Man the hunter. Aldine Publishings Co., Chicago. 
LYNCH, T., 1975a. Algunos problemas básicos del estadio de caza-recolección andina: Trashumancia. Estudios Atacameños 3.

_ 1975b. La cosecha inoportuna, trashumancia y el proceso de domesticación. Estudios Atacameños 3.

MENA, F., 1980. Una reevaluación espacial del Complejo Chiu Chiu. Informe de práctica. Departamento de Antropología, Universidad de Chile, Santiago.

- 1981. Consideraciones en torno a la movilidad de grupos en el Arcaico Tardío, II Región. Tesis de Grado. Departamento de Antropología, Universidad de Chile, Santiago.

MONTECINO, M., 1980. Ensayo para una geocronología desde Pleistoceno Superior al actual en el prealtiplano de la II Región: Toconce. Tesis de Grado. Departamento de Geografía, Universidad de Chile, Santiago.

NIEMEYER, H. y V. SCHIAPPACASSE, 1968. Investigaciones arqueológicas en laguna Miscanti (Provincia de Antofagasta). Revista Universitaria de la Universidad Católica año LIII.

- 1976. Los yacimientos arqueológicos de laguna Meniques. Anales de la Universidad del Norte 10, Antofagasta.

NUÑEZ, L., 1974. La agricultura prehistórica en los Andes Meridionales. Editorial Orbe, Santiago.

— 1975. Dinámica de grupos precerámicos en el perfil costaaltiplano, norte de Chile. Estudios Atacameños 3.

— 1978. Northern Chile. En Chronologies in New World archaeology, C. Meighan y Taylor (Eds.). Academic Press, Nueva York.

— 1978. Hipótesis de movilidad trashumántica en la Puna de Atacama: Quebrada de Tulan (nota preliminar). Actas del V Congreso Nacional de Arqueología Argentina, pp. 19-46.

— 1980Ms. Períodos culturales Paleoindio y Arcaico en los territorios áridos y semiáridos de Chile. Informe preliminar del Programa Paleoindio del Smithsonian Institution.

— 1981. Asentamientos de cazadores recolectores tardíos de la Puna de Atacama. Hacia el sedentarismo. Chungara 8: 137-168.

1983. Paleoindian and Archaic cultural periods in the arid and semiarid regions of Northern Chile. Advances in world archaelogy vol. 2, pp. 161-203.
— 1983. Paleoindio y Arcaico en Chile: Diversidad, secuencia y procesos. Ediciones Cuicuilco. Instituto Nacional de Antropología e Historia, México D. F.

- 1984. Tráfico de complementariedad de recursos entre las tierras altas y el Pacífico en el Area Centro Sur Andina. Tesis Doctoral. Universidad de Tokio, Tokio.

NUÑEZ, L. y J. VARELA, 1968. Sobre los recursos de agua y el poblamiento prehispánico de la costa del Norte Grande de Chile. Estudios Arqueológicos 3-4.

NUÑEZ, L. y T. DILLEHAY, 1979. Movilidad giratoria, armonía social y desarrollo en los Andes Meridionales; Patrones de tráfico e interacción económica (ensayo). Universidad del Norte, Antofagasta.

NUÑEZ, L. et al., 1974. Caleta Huelén 42: Una aldea temprana en el norte de Chile. Hombre y Cultura 2 (5).

- 1975. Un circuito trashumántico entre la costa de Pisagua y el borde occidental de la Pampa de Tamarugal. Estudios Atacameños 3.

ORELLANA, M., 1965. Informe de la primera fase del Proyecto Arqueológico Río Salado. Revista de Antropología 3.

- 1970. Excavaciones en la confluencia de los ríos Toconce y Salado Chico. Boletín de Prehistoria 2-3.

- 1969. Nuevas investigaciones en río Salado. Actas del V Congreso Nacional de Arqueología. La Serena.

1971. Informe de las excavaciones de Loa Oeste 3. Boletín de Prehistoria 3 (4).

— 1973. Primera aplicación del sistema de computación en materiales arqueológicos del norte de Chile. Actas del VI Congreso de Arqueología de Chile. Boletín de Prehistoria, vol. especial.

POLLARD, G., 1971. The cultural ecology of ceramic stage settlement in the Atacama Desert. Ph. D. Thesis. Columbia University, University Microfilms International, Ann Arbor.

SERRACINO, J., 1975. Los movimientos de los cazadores y recolectores en la Cordillera de los Andes, entre la Lat. $21^{\circ}$ y $26^{\circ}$ y Long. $67^{\circ}$ y $70^{\circ} 22^{\prime}$. Estudios Atacameños 3 .

1976. Patrones de asentamientos: Industrias Tambilliense. Anales de la Universidad del Norte 10, Antofagasta.

SERRACINO, J. y C. THOMAS, 1971. Excavación del yacimiento Confluencia 1. Boletín de Prehistoria 3 (4). 